\title{
EGFR-TKI resistance promotes immune escape in lung cancer via increased PD-L1 expression
}

\author{
Shunli Peng ${ }^{1 \dagger}$, Rong Wang ${ }^{1 \dagger}$, Xiaojuan Zhang ${ }^{1}$, Yueyun Ma ${ }^{1}$, Longhui Zhong ${ }^{1}, \mathrm{Ke} \mathrm{Li}^{2}$, Akihiro Nishiyama ${ }^{3}$,
} Sachiko Arai $^{3}$, Seiji Yano ${ }^{3 *}$ and Wei Wang ${ }^{1^{*}}$

\begin{abstract}
Background: The ATLANTIC trial reported that higher PD-L1 expression in tumors was involved in a higher objective response in patients with $E G F R^{+} / A L K^{+}$non-small cell lung cancer (NSCLC), indicating the possibility of antiPD-1/PD-L1 therapy as a third-line (or later) treatment for advanced NSCLC. Therefore, the determination of status and regulatory mechanisms of PD-L1 in EGFR mutant NSCLC before and after acquired EGFR-TKIs resistance are meaningful.

Methods: The correlation among PD-L1, C-MET, and HGF was analyzed based on TCGA datasheets and paired NSCLC specimens before and after acquired EGFR-TKI resistance. EGFR-TKI resistant NSCLC cells with three wellknown mechanisms, c-MET amplification, hepatocyte growth factor (HGF), and EGFR-T790M, were investigated to determinate PD-L1 expression status and immune escape ability. PD-L1-deleted EGFR-TKIs sensitive and resistant cells were used to evaluate the immune escape ability of tumors in mice xenograft models.

Results: Positive correlations were found among PD-L1, C-MET, and HGF, based on TCGA datasheets and paired NSCLC specimens. Moreover, the above three resistant mechanisms increased PD-L1 expression and attenuated activation and cytotoxicity of lymphocytes in vitro and in vivo, and downregulation of PD-L1 partially restored the cytotoxicity of lymphocytes. Both MAPK and PI3K pathways were involved in the three types of resistance mechanism-induced PD-L1 overexpression, whereas the NF-kappa B pathway was only involved in T790M-induced PD-L1 expression.

Conclusions: HGF, MET-amplification, and EGFR-T790M upregulate PD-L1 expression in NSCLC and promote the immune escape of tumor cells through different mechanisms.
\end{abstract}

Keywords: PD-L1, EGFR-TKIs resistance, Signaling pathways, Lung cancer, Immunotherapy

\section{Background}

Lung cancer is the most common cancer and a leading cause of death from cancer in men and women in the United States [1]. Epidermal growth factor receptortyrosine kinase inhibitors (EGFR-TKIs), which are classic small molecule inhibitors used in targeted treatments, have been shown to prolong the survival time of patients

\footnotetext{
* Correspondence: syano@staff.kanazawau.ac.jp; wangwei9500@hotmail.com

tShunli Peng and Rong Wang contributed equally to this work.

${ }^{3}$ Divisions of Medical Oncology, Cancer Research Institute, Kanazawa

University, Kanazawa, Ishikawa, Japan

${ }^{1}$ Department of Radiation Oncology, Nanfang Hospital, Southern Medical

University, Guangzhou, People's Republic of China

Full list of author information is available at the end of the article
}

with tumours harboring EGFR-activating mutations from less than 1 year to approximately 20-30 months [2-5]. Although third-generation EGFR-TKIs could overcome EGFR mutation threonine 790 (T790M) resistance and are becoming the new first-line standard in EGFR mutant non-small cell lung cancer (NSCLC), acquired resistance is virtually inevitable [6]. Multiple resistant mechanisms have been identified, including the activation of cMET signal pathway [7, 8], MET amplification, hepatocyte growth factor (HGF) and MET overexpression], human epidermal growth factor receptor 2 (HER2) amplification [6], and EGFR C797S, L792H and G796R mutations [9]. Among the above mechanisms, high-level MET 
amplification (11-26\%), HGF secretion and MET overexpression were frequently detected in EGFR-TKIs resistant NSCLC, especially acquired third generation EGFRTKIs resistance [10], which indicate that the (MET)/hepatocyte growth factor (HGF) pathway becomes an important resistant mechanism especially in third-generation EGFR-TKIs resistant NSCLC. Therefore, the identification of new therapeutic methods or agents for the treatment of EGFR-TKI resistant lung cancer is imperative.

Immune checkpoint therapy, which is based on negative regulatory mechanisms and targeted enhancement of the anti-tumour immune response [11], is a novel and important therapeutic strategy for lung cancer, especially for patients with advanced non-small-cell lung cancer (NSCLC) [12]. Some retrospective analyses suggest that NSCLC tumours with EGFR mutation or anaplastic lymphoma kinase $(A L K)$ rearrangements $\left(E G F R^{+} / A L K^{+}\right)$do not respond well to these treatments when compared with $E G F R^{-}$/ $A L K$ tumours, indicating that EGFR mutant patients are not ideal candidates for anti-PD-1/PD-L1 therapies, compared to patients with $K R A S$ mutation or wild-type EGFR [13-16]. Recently, the results of the ATLANTIC trial [17, 18] showed the possible efficacy of durvalumab (anti-human PD-1 monoclonal antibodies) as a third-line (or later) treatment for advanced NSCLC, including $E G F R^{+} / A L K^{+}$ NSCLC. In addition, the PD-L1 expression level in tumour cells may also be involved in the objective responses of patients with $E G F R^{+} / A L K^{+}$NSCLC $[17,19]$. Moreover, Su et al. [20] reported that one patient with de novo resistance to EGFR-TKIs in addition to PD-L1 and CD8 dual positivity experienced a favorable response to anti-PD-1 therapy. Thus, checkpoint therapies should not be completely excluded from candidate strategies for the treatment of NSCLC patients who acquire resistance to EGFR-TKIs, and unfolding the regulatory mechanisms of PD-L1 in EGFR-TKI resistant NSCLC is thus imperative.

It has been reported that EGFR activation contributed to the upregulation of PD-L1 expression in lung cancers [21], and the expression level of PD-L1 can be decreased by EGFR-TKIs. However, the regulatory mechanisms of PD-L1 and the activity of immune checkpoint inhibitors in EGFR-TKI resistant lung cancer remain unclear. Therefore, we investigated the influence of three important EGFR-TKI resistant mechanisms (HGF, $c-M E T$ amplification and EGFR-T790M) on PD-L1 expression and the immune escape capability of tumours before and after acquired EGFR-TKIs resistance, and explored the regulation mechanisms of PD-L1 in different resistant subtypes.

\section{Methods}

\section{Cell lines and reagents}

The EGFR mutant human lung adenocarcinoma cell lines, HCC827 and H1975, were purchased from the American Type Culture Collection (ATCC) Manassas,
Virginia, USA. The EGFR mutant human lung adenocarcinoma cell line PC-9 was purchased from Immuno Biological Laboratories Co., Ltd., Gunma, Japan. The transfected-human renal derived 293FT cell line was purchased from the Type Culture Collection of the Chinese Academy of Sciences, Shanghai, China. PC-9 and HCC827 cell lines were maintained in RPMI 1640 supplemented medium and the 293FT cell line was maintained in Dulbecco's modified Eagle's medium (DMEM). All of the cell lines were cultured as descried previously described [22]. The genome-scale CRISPRCas9 knockout lentiviruses (lenti-sgRNA-EGFPMCS, lenti-Cas 9-puro) were used to construct the PD-L1 gene-deleted cell lines and relative negative control cells (PC-9 PD-L1-, PC-9R PD-L1-, PC-9 ${ }^{\text {PD-L1+ }}$, and PC-9R ${ }^{\mathrm{PD}-\mathrm{L} 1+}+$ ) according to the manufacturer's instructions (Shanghai Genechem Co., Ltd., Shanghai, China).

Gefitinib (a selective EGFR inhibitor), TAK-733 (a selective allosteric inhibitor of MEK), PF-04691502 (an ATP competitive dual PI3K/mTOR inhibitor), and IMD 0354 (an inhibitor of IKK $\beta$ ) were purchased from Selleck Chemicals (Houston, TX, USA), and dissolved in dimethyl sulfoxide (DMSO, MP Biomedicals, California, USA) at a concentration of $10 \mathrm{mmol} / \mathrm{L}$. Recombinant human HGF Protein was purchased from R\&D Systems (Minnesota, USA). Anti-PD-L1 monoclonal antibody (MIH1) was purchased from eBioscience (California, USA).

\section{Cell growth assay and western blotting}

Cell growth assay and western blotting were performed as previously described [23]. Cell growth assay was measured by 3-(4,5-dimethylthiazol-2-yl)-2,5-diphenyl tetrazolium (MTT) assay. Tumor cells (2000/well) were plated into each well of 96-well plates with culture medium. Various concentrations of indicated agents were added to each well $24 \mathrm{~h}$ later, and further incubated for $72 \mathrm{~h}$. Then, MTT solution was added and incubated for another $2 \mathrm{~h}$. The media containing MTT solution were removed, and the dark blue crystals were dissolved by adding $100 \mu \mathrm{L}$ of DMSO. The absorbance was measured with a microplate reader at test and reference wavelengths of 490 and $550 \mathrm{~nm}$. The percentage of growth is shown relative to the untreated controls. Each experiment was done at least in triplicate and thrice independently. Western blotting analysis was performed as described previously $[24,25]$ and the quantitation results were summarized (Additional file 3 ). The primary antibodies used in this study included anti-Met $(25 \mathrm{H} 2)$, anti-phospho-Met(Y1234/Y1235), anti-EGFR, anti-phospho-EGFR (Y1068), anti-Akt, anti-phospho-Akt (Ser473), anti-(Erk1/2) (137F5), anti-PD-L1 (\#13684) and antiphospho-p44/42 MAPK (Erk1/2) (Thr202/Tyr204), which were purchased from Cell Signaling Technology, 
Massachusetts, USA. Anti-human CD274 (PD-L1, B7-H1) antibodies (Function Grade Purified) were purchased from eBioscience, California, USA.

\section{Flow cytometric analysis}

The human CD3 (PE HIT3a), CD4 (PE-cy5 RPA-T4), CD8 (FITC RPA-T4), Hu CD1a (PE), Hu CD83 (FITC), $\mathrm{Hu}$ CD16 (FITC), Hu CD56 (PE-Cy7), Hu HLA-DR (APC), and $\mathrm{Hu}$ HLA-ABC (FITC) antibodies were purchased from BD Pharmingen. Anti-PD-L1 (E1L3N, 1:400 dilution), anti-rabbit IgG $(\mathrm{H}+\mathrm{L})$ secondary antibodies, and $\mathrm{F}\left(\mathrm{ab}^{\prime}\right) 2$ - fragment (Alexa Fluor 555 Conjugate, \#4413) were purchased from Cell Signaling Technology. The mean fluorescence intensity (MFI) and mean specific fluorescence intensity (MSFI) were measured to evaluate PD-L1 expression levels, and MSFI was calculated as the ratio of the MFI of anti-PD-L1 antibody to that of the control antibody [26]. Each experiment was performed at least in triplicate, and thrice independently.

\section{Isolation and activation of human PBMC and T lymphocytes}

Peripheral blood mononuclear cells (PBMCs) were isolated using density-gradient-centrifugation-(Ficoll), and the activation of $\mathrm{T}$ cells was performed as previously described $[27,28]$. Briefly, PBMCs were isolated according to the manufacturer's instructions and then cultured in RPMI 1640 and 10\% FBS overnight. Then, the supernatant $\mathrm{T}$ cells were collected and stimulated for 2 days with PHA $(10 \mu \mathrm{g} / \mathrm{mL})$ and rhIL-2 $(4000 \mathrm{UI} / \mathrm{mL})$ to promote the proliferation and activation of $\mathrm{T}$ lymphocytes. Finally, T lymphocytes were cultured with rhIL-2 (2000 $\mathrm{UI} / \mathrm{mL}$ ) in RPMI 1640 and $10 \%$ FBS to obtain the survival of activated $\mathrm{T}$ lymphocytes.

\section{Xenograft studies in NOD-SCID mice}

The in vivo experimental project was approved by Nanfang Hospital Animal Ethic Committee (NFYY2016-63), and four-week-old male NOD-SCID mice that were used in the in vivo experiment were purchased and maintained in a specific pathogen-free (SPF) institution of experimental animal center of Nanfang Hospital, Guangzhou, China. Firstly, four-week-old male NODSCID mice were randomly assigned into 4 groups, and PC-9 ${ }^{\text {PD-L1- }}$, PC-9R ${ }^{\text {PD-L1- }}$, PC-9 ${ }^{\text {PD-L1+ }}$, and PC-9 ${ }^{\text {PD-L1+ }}$ cells $\left(4 \times 10^{6} /\right.$ per xenograft) were injected subcutaneously to establish 4 xenograft tumour models $(N=8)$. Then, each xenograft tumour model was randomly assigned into 2 group $(N=4)$ with intraperitoneal injection of phosphate buffer saline (PBS) or human immunocyte mixtures consisting of human PBMC $\left(5 \times 10^{6} /\right.$ per mouse) and activated T lymphocytes $\left(1 \times 10^{7} /\right.$ per mouse $)$ after tumour injection on days $0,7,14$, and 21.Tumour volumes were measured with Vernier calipers along their width (a) and length (b), and tumour volume was calculated using the eq. $T V=\left(a^{2} b\right) / 2$. Tumor regression rate $=$ (Tumour volume in NOD-SCID mice after immunocyte mixtures treatment / tumour volume in NOD-SCID mice after PBS treatment) $\times 100 \%$. All of the mice were housed in a pathogen-free environment.

\section{Specimens and TCGA data}

In total, 16 tumour specimens with EGFR-activating mutations were provided by the Kanazawa University Hospital (Kanazawa, Japan). Detailed patient information for the EGFR-TKI resistant specimens is described in Additional file 2: Table S1. The TCGA datasets of lung adenocarcinoma (PanCancer Atlas and provisional) were retrieved from cBioProtal (http://www.cbioportal.org/ study?id=luad_tcga\#summary). The detailed analysis is provided in the Additional file 1: Supplementary materials and methods.

\section{Statistical analysis}

All data were presented as the mean \pm standard deviation (SD), and differences between the means were examined by student's $t$ test or one-way ANOVA using statistical software (SPSS, version 20, IBM Corp., Armonk, USA). Differences with a value of $P<0.05$ were considered statistically significant. All of the experiments were performed at least thrice.

\section{Results}

Changes in PD-L1 expression after acquiring EGFR-TKI resistance in NSCLC

Based on the paired specimens from the same patient (EGFR-L858R mutation) who initially benefitted from gefitinib treatment and then acquired resistance (Fig. 1a), we investigated the change in tumours before and after acquired EGFR-TKI resistance. The results showed that PD-L1 expression in specimens increased from $<1 \%$ to $\geq 50 \%$ after the patient acquired gefitinib resistance. Moreover, in the resistant specimens, EGFR-T790M mutation could not be detected, whereas high c-MET expression was measured (Fig. 1a, Additional file 2: Table S1). To clarify the expression status of PD-L1 in EGFRTKIs resistant NSCLC and determine why PD-L1 expression in the tumours of these patients changed after acquired EGFR-TKIs resistance, we collected specimens from 15 NSCLC patients who acquired EGFR-TKI resistance (Additional file 2: Table S1) and detected PD-L1 expression via PD-L1 IHC $22 \mathrm{C} 3$ pharmDx. Figure $1 \mathrm{~b}$ shows that the percentage of no, low, or high PD-L1 expression among the 15 EGFR-TKI resistant specimens was $13.3,60$ and $26.7 \%$, respectively. These results suggest that a subgroup of EGFR-TKI resistant NSCLC tumours expresses a high level of PD-L1. 

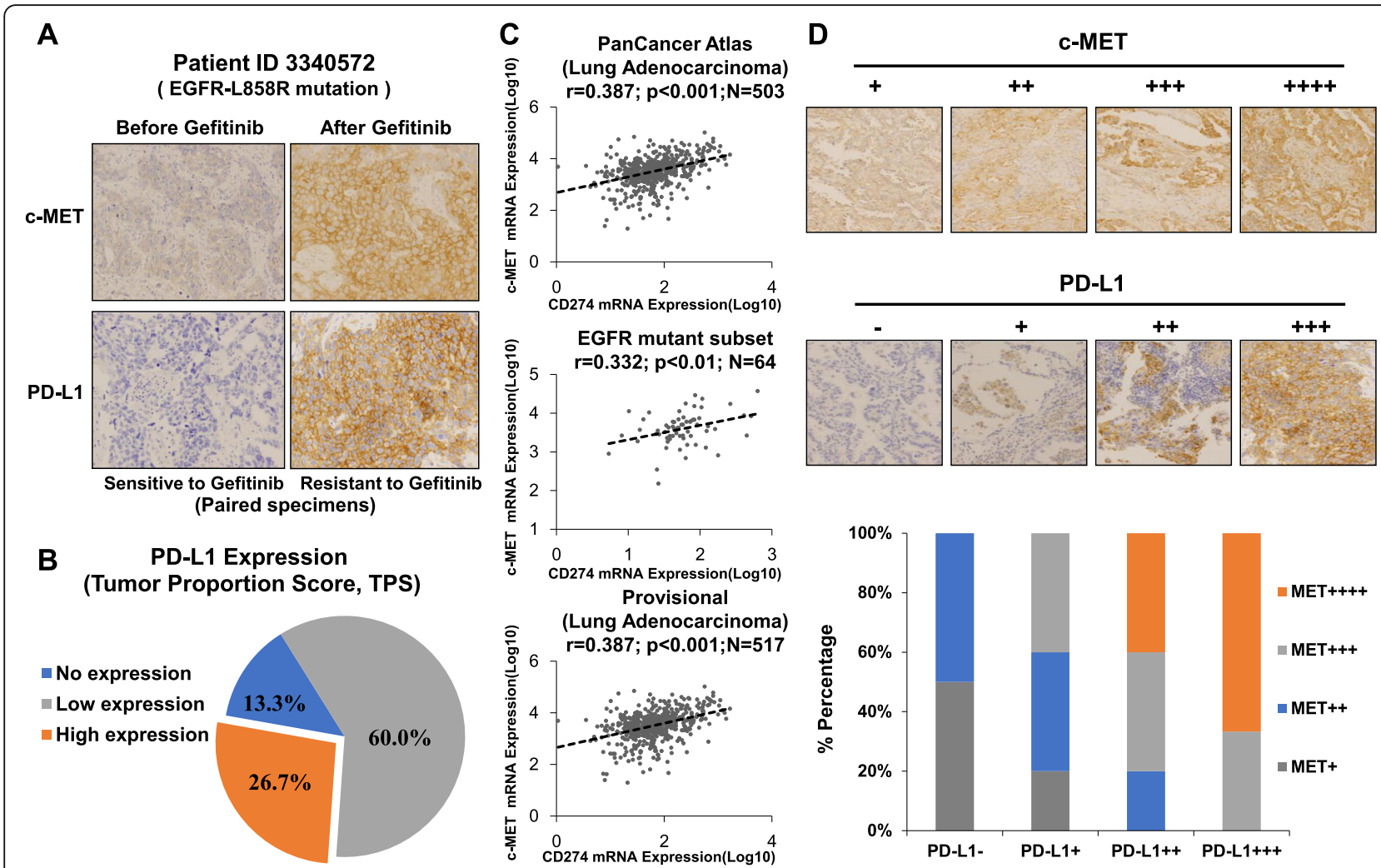

Fig. 1 The expression of PD-L1 in NSCLC changes after acquisition of EGFR-TKIs resistance based on the patient biopsy specimens and TCGA datasets. a PD-L1 expression increased in a subgroup of EGFR-TKI resistant specimens. PD-L1 and C-MET expression status in paired specimens before and after acquired gefitnib resistance were measured by IHC staining. b PD-L1 expression status in EGFR-TKI resistant NSCLC specimens ( $N=15)$. $\mathbf{c}$ and $\mathbf{d}$ The correlation coefficient between PD-L1 (CD274) and C-MET in lung adenocarcinoma and EGFR mutant subsets based on the TCGA datasets (Lung Adenocarcinoma, PanCancer Atlas and Provisional) and in EGFR-TKI resistant NSCLC specimens

Since we found that $M E T^{+}$mutant NSCLC patients seem to have higher PD-1, PD-L1 expression compared with the $E G F R^{+}$and $K R A S^{+}$mutant subgroups (Additional file 1: Figure S1), and high expression of cMET and PD-L1 were detected in gefitinib resistant specimens (Fig. 1a), we investigated whether the upregulation of PD-L1 in these patients was related to the cMET activation. Thus, we analyzed the correlation between PD-L1 (CD274) and $c-M E T$ based on two TCGA datasets (Lung Adenocarcinoma, PanCancer Atlas, provisional). As shown in Fig. 1c, the coefficient of correlation $\left(\mathrm{R}^{2}\right)$ of $P D-L 1$ and $c-M E T$ expression in lung adenocarcinoma or the EGFR mutant subgroup was $0.332-0.387(p<0.05$, Fig. 1c). To further investigate the correlation between PD-L1 and c-MET in EGFR-TKI resistant NSCLC, we measured the PD-L1 and c-MET expression in 15 EGFR-TKI resistant biopsies. The results revealed a higher percentage of c-MET expression in specimens with high expression of PD-L1; the coefficient of correlation between PD-L1 and c-MET was $0.591(p<0.05$, Fig. 1d), indicating a positive correlation between PD-L1 and c-MET in EGFR-TKI resistant NSCLC.
HGF induces PD-L1 expression in EGFR-mutant NSCLC cells and moderates proliferation and cytotoxicity of $T$ lymphocytes

HGF not only activates the c-MET signaling pathway to induce EGFR-TKIs resistance in lung adenocarcinomas $[23,29]$, but it also promotes the transcription of the endogenous $c-M E T$ gene [30]. Based on the positive correlation between PD-L1 and c-MET expression (Fig. 1c-d), we investigated whether HGF influences PD-L1 expression in EGFR-TKI resistant NSCLC. Based on the two TCGA datasets (Lung Adenocarcinoma, PanCancer Atlas and Provisional), the coefficient of correlation between HGF and PD-L1 expression was 0.224, and 0.227, respectively $(p<0.01)$ (Fig. 2a). To further confirm the influence of HGF on PD-L1 in EGFR-TKI resistant NSCLC, we added HGF $(50 \mathrm{ng} / \mathrm{L})$ to the culture medium of EGFR mutant NSCLC cells (PC-9, HCC827) to establish the HGF-mediated EGFR-TKI resistant NSCLC cell models. The results showed that PD-L1 expression was increased after stimulation of HGF $(50 \mathrm{ng} / \mathrm{L}$, Fig. 2b-d, Additional file 1: Figure S2). Moreover, because the PD1/PD-L1 axis promotes tumour cell escape from immune surveillance by inhibiting the proliferation, 


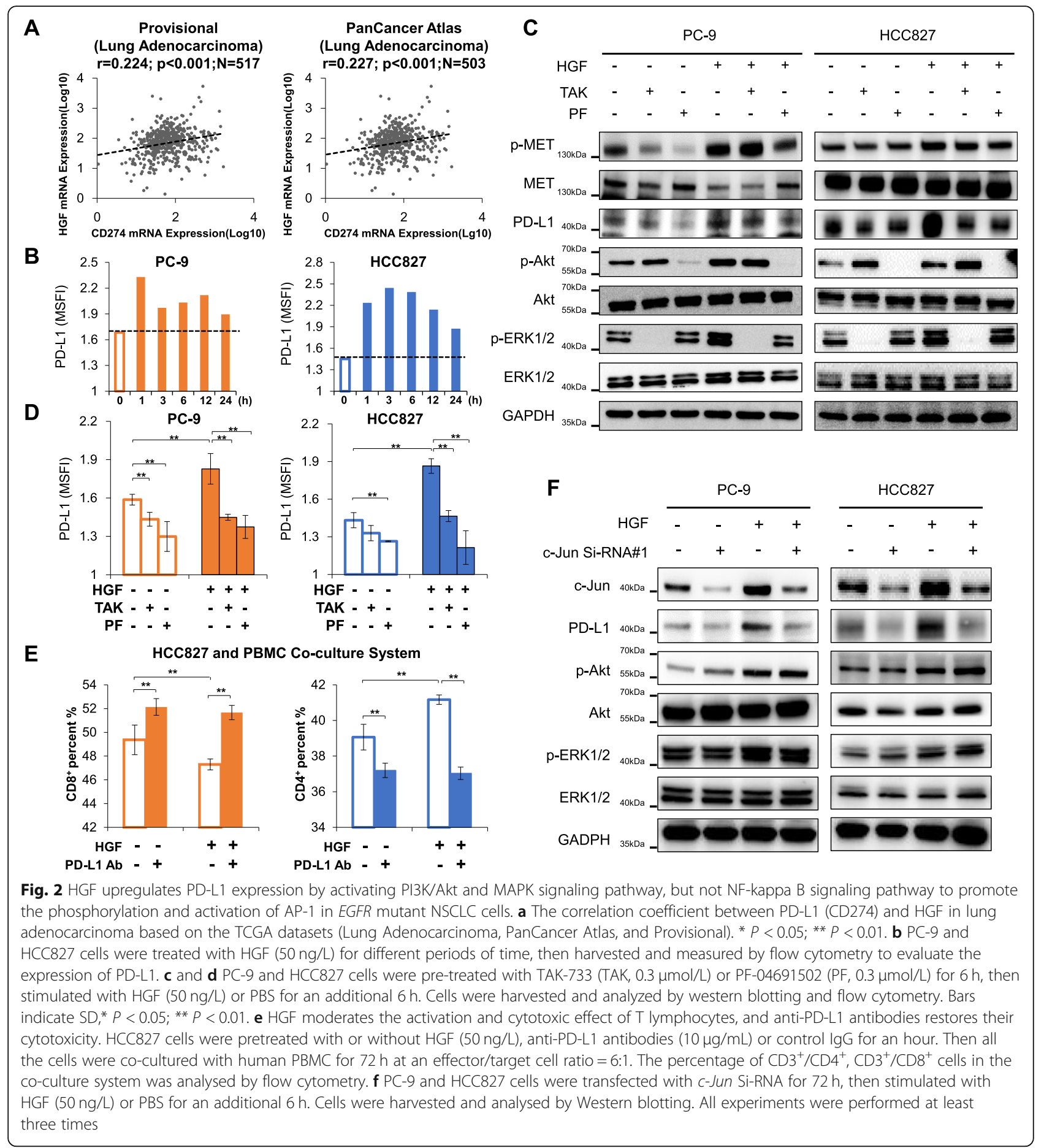

activation and cytotoxicity of $\mathrm{T}$ lymphocytes [31], we investigated whether HGF-induced upregulation of PDL1 moderates the proliferation and cytotoxicity of $\mathrm{T}$ cells in vitro. Peripheral blood mononuclear cells (PBMC) cells of healthy donators were collected and cultured with tumour cells (HCC827) to evaluate the percentage and activation of $\mathrm{CD}^{+} \mathrm{T}$ cells. As shown in Additional file 1: Figure S3A, the percentage of dendritic cells (DCs) in PBMCs was $4-5 \%$, indicating the capacity of antigen presentation to naïve $\mathrm{T}$ cells. As expected, the percentage of $\mathrm{CD}^{+} \mathrm{T}$ cells in PBMCs increased after co-culturing with tumour cells, indicating the proliferation and activation of anti-tumour specific $\mathrm{T}$ cells (Additional file 1: Figure S3B and C). HGF did not change 
HLA-ABC expression in HCC827 cells (Additional file 1: Figure S3D). However, treatment with HGF decreased the percentage of $\mathrm{CD}^{+} \mathrm{T}$ cells and the secretion of IFN- $\gamma$ in the co-culture system (Fig. 2e, Additional file 1: Figure S4A), indicating that HGF weakens the cytotoxicity of T cells toward tumours. In addition, anti-PD-L1 antibodies partially increased the percentage of $\mathrm{CD}^{+} \mathrm{T}$ cells and the secretion of IFN- $\gamma$ in the co-culture system. The percentage of $\mathrm{CD}^{-} \mathrm{CD} 16^{+} \mathrm{CD} 56^{+} \mathrm{NK}$ cells in PBMCs is approximately $1 \%$ (Additional file 1: Figure S4B) with undetectable cytotoxicity to PC-9 or HCC827 cells in the co-culture system (data not shown). These results suggest that HGF may promote immune escape of tumour cells via overexpression of PD-L1 in EGFR-TKI resistant NSCLC cells.

\section{HGF induces PD-L1 expression in NSCLC cells by} activation of PI3K/Akt, MAPK, and AP-1 (activator protein 1) Because HGF may increase EGFR-TKI resistance, PDL1 expression, and immune escape in NSCLC, we explored the regulatory mechanisms of PD-L1 expression in HGF-mediated EGFR-TKI resistant NSCLC tumours. As the phosphoinositide 3-kinase (PI3K)/Akt and mitogen-activated protein kinase (MAPK) signaling pathways are critical to EGFR-TKIs resistance of EGFR mutant NSCLC cells [23] and the NF-kappa B pathway is reported to be activated by HGF in many tissues [32, 33], we investigated whether these three pathways are involved in HGF-mediated PD-L1 expression. Consistent with our previous reports [29, 34], both the PI3K/Akt and MAPK signaling pathways were activated after treatment with an HGF, PI3K inhibitor (PF-04691502) and MEK inhibitor (TAK733), and successfully inhibited the phosphorylation of Akt and ERK1/2 (Fig. 2c). Moreover, PD-L1 expression increased after stimulation of $\mathrm{HGF}$, while inhibiting PI3K/Akt or MAPK signal pathway abolished HGF induced-PD-L1 upregulation (Fig. 2c-d). However, inhibition of NF-kappa B pathway had no significant influence on PD-L1 expression after stimulation of HGF (Additional file 1: Figure S5).

Activator protein (AP-1), a transcription factor that consists of a variety of dimers composed of members including c-Jun and c-FOS, has been reported to be activated by the PI3K and MAPK signaling pathways and could promote transcription of PD-L1 in melanoma cells [35]. Therefore, we hypothesized that AP-1 is involved in HGF-induced PD-L1 expression in lung cancer. Figure $2 \mathrm{f}$ shows that the knockdown of c-Jun decreased HGF-induced PD-L1 expression, even though the PI3K/Akt and MAPK pathways were activated. These results suggest that the PI3K/Akt, MAPK pathways, and AP-1 are involved in HGF-induced PD-L1 upregulation in EGFR mutant NSCLC.
c-MET amplification mediated-EGFR-TKIs resistance upregulates PD-L1 expression and promotes immune escape ability of EGFR-mutant NSCLC cells

As $c$-MET amplification increases c-MET expression [36], we explored whether $c-M E T$ amplification could increase the expression of PD-L1. We generated $c$ $M E T$-amplified EGFR-TKI resistant clones by exposing EGFR mutant NSCLC cells (PC-9) to increasing concentrations of gefitinib over 6 months as previously described [36, 37]. Three clones from the gefitinib-resistant PC-9 cells showed $c-M E T$ amplification and acquired resistance to gefitinib (Fig. 3a-c). Clone 2 (named PC-9R) was selected for subsequent experiments due to the high expression of the $c-M E T$ gene. Figure 3d and Additional file 1: Figure S6 show that c-MET and PD-L1 expression in PC-9R cells was higher than in PC-9 cells. Moreover, gefitinib successfully decreased PD-L1 expression in PC-9 cells but had no significant influence on PD-L1 expression on PC-9R cell. In contrast, $c-M E T$ siRNA effectively decreased PD-L1 expression in PC-9R cells (Fig. 3e, Additional file 1: Figure S7). In both PC-9 and PC-9R cells, $c-M E T$ siRNA combined with gefitinib effectively downregulated PD-L1 expression. These results suggest that $c-M E T$ amplification upregulates PD-L1 expression in EGFR-TKI resistant NSCLC cells.

To evaluate the immune escape capability of PC-9 and PC-9R cells, we co-cultured PBMC cells with PC9 or PC-9R cells and found that the percentage of $\mathrm{CD}^{+} \mathrm{T}$ cells and secretion level of IFN- $\gamma$ was lower in the presence of $\mathrm{PC}-9 \mathrm{R}$, although $\mathrm{PC}-9$ and $\mathrm{PC}-9 \mathrm{R}$ cells expressed similar levels of HLA-ABC (Fig. 4a-b, Additional file 1: Figure S8). In addition, anti-PD-L1 antibodies increased percentage of $\mathrm{CD}^{+} / \mathrm{CD}^{+}$cells $\left(\mathrm{CD}^{+} \mathrm{T}\right.$ cells) and secretion of IFN- $\gamma$ in both coculture systems. These results suggest that $c-M E T$ amplification may promote the immune escape of EGFR-TKI resistant NSCLC cells partially through overexpression PD-L1.

\section{PI3K/Akt and MAPK, but not NF-kappa B, signaling} pathways are involved in C-MET amplification-induced upregulation of PD-L1 in EGFR-TKIs resistant NSCLC cells We investigated whether PI3K, MAPK, and NF-kappa B signaling pathways participate in the upregulation of PD-L1 mediated by $c-M E T$ amplification. As shown in Fig. 4c-e, TAK733 seems to be more effective than PF-04691502 in PD-L1 downregulation in PC-9 cells, which means that the PI3K/Akt pathway may be less important than the MAPK signaling pathway in the regulation of PD-L1 in gefitinib-sensitive cells. However, both PF-04691502 and TAK733 effectively decrease PD-L1 expression in PC-9R cells, which indicates that both PI3K/Akt and MAPK pathways seem 


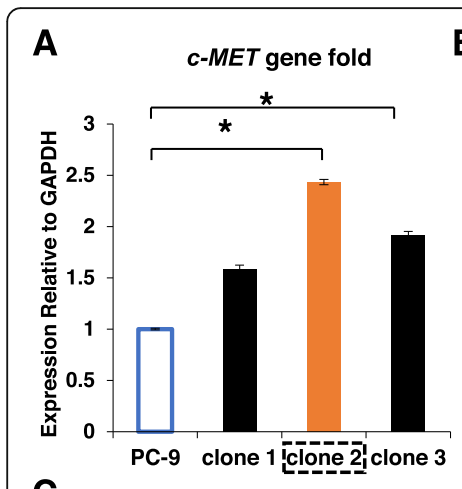

C

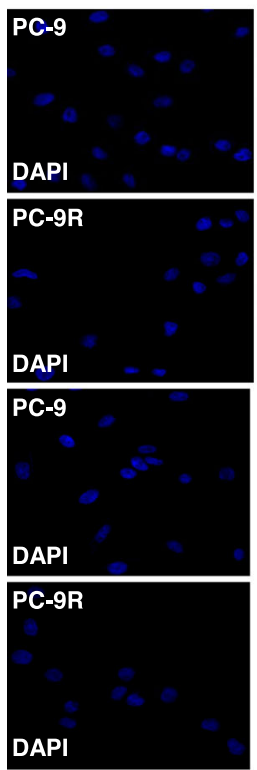

B

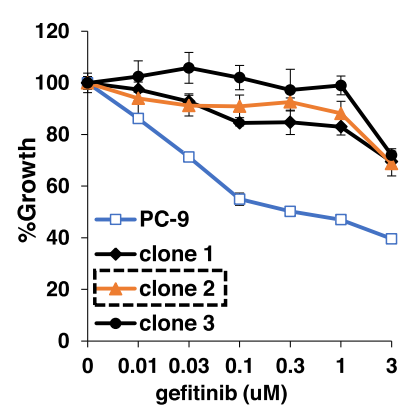

gefitinib (uM)
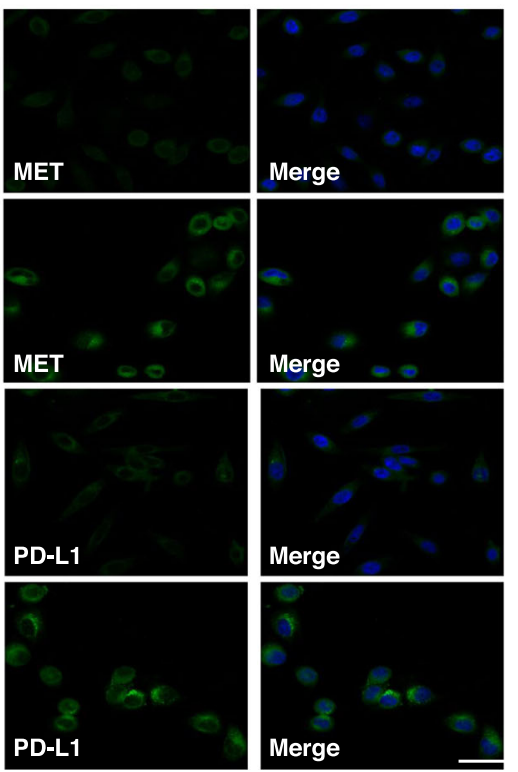

D

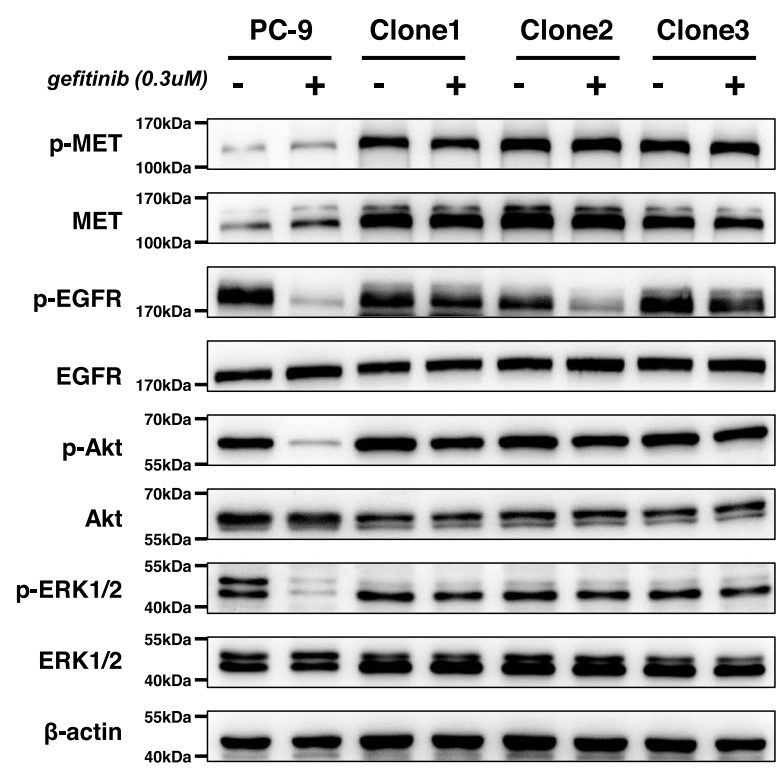

E

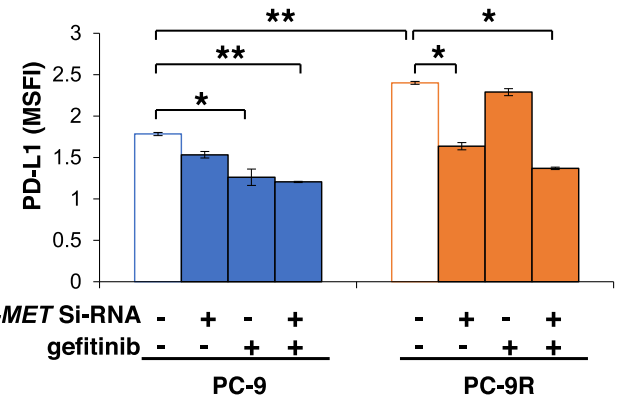

Fig. 3 C-MET amplification upregulated PD-L1 expression in EGFR-TKI resistant NSCLC cells. a Three clones were picked from gefitinib-resistant PC9 cells, and incubated with increasing concentrations of gefitinib (1 $\mu \mathrm{mol} / \mathrm{L}$, final concentration) over 6 months. C-MET amplification was measured by RT-qPCR. Clone 2 was named PC-9R and used for further study. Bars indicate SD.* $P<0.05$. b PC-9 and the three clones were treated with various concentrations of gefitinib, and cell growth was determined after $72 \mathrm{~h}$ of stimulation using the MTT assay. $\mathbf{c}$ Expression of cMET and PD-L1 protein in PC-9 and PC-9R cells was measured by immunofluorescence staining and visualized using a laser confocal microscopy ( $\times 400)$ (bars $=200 \mu \mathrm{m})$. d PC-9 cells and three clone cells were treated with gefitinib $(1 \mu \mathrm{mol} / \mathrm{L})$ for $12 \mathrm{~h}$, and the lysates were harvested. Indicated proteins were determined by western blotting. e PC-9 and PC-9R cells were treated with or without c-MET siRNA for 48 h, and cultured with or without treatment of gefitinib (1 $\mu \mathrm{mol} / \mathrm{L})$. After further $12 \mathrm{~h}$, cells were collected and PD-L1 expression was examined by flow cytometry. All of the experiments were performed at least thrice

to be critical after acquired gefitinib resistance mediated by $c-M E T$ amplification. Moreover, inhibition of the NF-kappa B pathway downregulated PD-L1 expression in PC-9 cells but not PC-9R cells (Additional file 1: Figure S9), suggesting that the NF-kappa B pathway is less important in $c-M E T$ amplificationinduced PD-L1 expression, even though the NF-kappa B pathway is associated with EGFR-induced PD-L1 expression [38]. Taken together, these results suggest that the PI3K/Akt and MAPK, but not the NF-kappa $B$, signaling pathways are critical in the upregulation of PD-L1 induced by $c-M E T$ amplification in EGFRTKI resistant NSCLC cells.
EGFR-T790M mutation upregulates PD-L1 expression through the PI3K/Akt, MAPK, and NF-kappa B signaling pathways

EGFR-T790M mutation (T790M) accounts for the greatest number of cases of acquired resistance to first generation EGFR-TKIs. To investigate the relationship between $T 790 M$ and PD-L1, we transfected the EGFRexon 19 deletion (19Del) or EGFR-T790M mutation into 293FT cells to mimic the status of NSCLC before and after developing resistance to EGFR-TKIs via T790M mutation. Figure $5 \mathrm{a}$ and $\mathrm{b}$ show that the transfection of 19Del and/or T790M induced a high level of EGFR activation, and gefitinib effectively inhibited the 

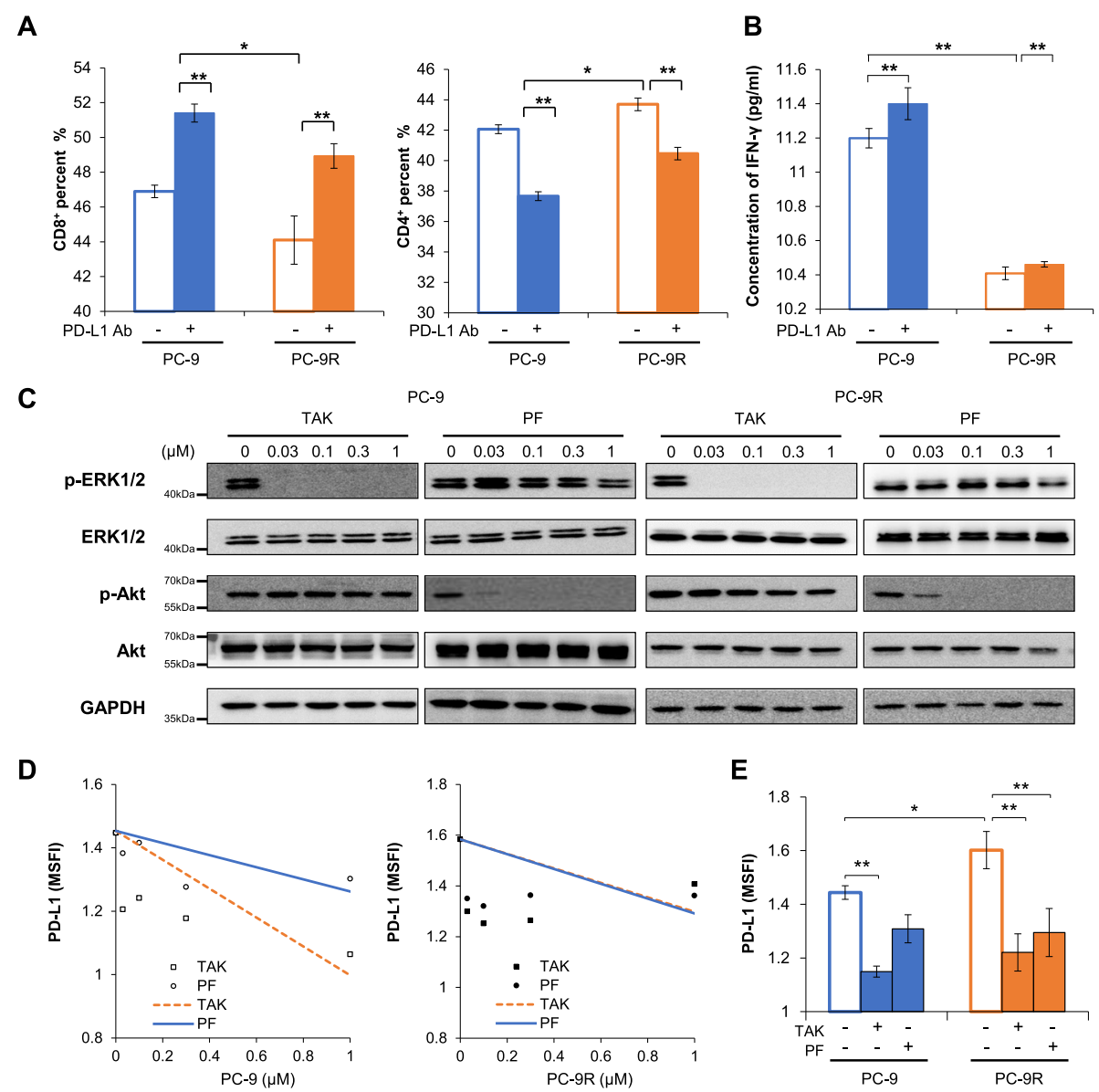

Fig. 4 a C-MET amplification mediates PD-L1 moderated the activation and cytotoxic effect of T lymphocytes, and anti-PD-L1 antibodies restored the cytotoxicity of T lymphocytes. PC-9 or PC-9R cells were pretreated with anti-PD-L1 antibodies $(10 \mu \mathrm{g} / \mathrm{mL})$ or control lgG for an hour, then cocultured with human PBMC for a further $72 \mathrm{~h}$ at an effector/target cell ratio $=6: 1$. The percentage of $\mathrm{CD}^{+} / \mathrm{CD}^{+}, \mathrm{CD}^{+} / \mathrm{CD}^{+}$cells in the coculture system was analyzed by flow cytometry. $\mathbf{b}$ IFN- $\gamma$ concentration in the supernatant of co-culture systems. PC-9 or PC-9R cells were pretreated with anti-PD-L1 antibodies $(10 \mu \mathrm{g} / \mathrm{mL})$ or control lgG for an hour, then co-cultured with human PBMC for further $72 \mathrm{~h}$ at an effector/ target cell ratio $=6: 1$. The concentration of IFN- $\gamma$ in the supernatant was detected by human IFN- $\gamma$ ELISA assay (multi sciences company, EK1802). Bars indicate SD; ** $P<0.01$.c-e PI3K/Akt and MAPK signaling pathways are involved in C-MET amplification mediated upregulation of PD-L1 in EGFR-TKI resistant lung cancer. $\mathbf{c}$ and $\mathbf{d}$ TAK-733 (MEK inhibitor) and PF-04691502 (dual PI3K/mTOR inhibitor) successfully inhibited the MAPK and PI3K signaling pathways. PC-9 and PC-9R cells were incubated with various concentrations of TAK-733 or PF-04691502 in concentration of 0, 0.01, $0.1,0.3,1 \mu \mathrm{mol} / \mathrm{L}$ respectively. After $12 \mathrm{~h}$, the cells were harvested and analysed by western blotting and flow cytometry. e PC-9 and PC-9R cells were incubated with TAK-733 $(0.3 \mu \mathrm{mol} / \mathrm{L})$ or PF-04691502 $(0.3 \mu \mathrm{mol} / \mathrm{L})$ for $12 \mathrm{~h}$, then harvested and analyzed by flow cytometry. Bars indicate SD. * $P<0.05,{ }^{* *} P<0.01$. All of the experiments were performed at least thrice

phosphorylation of EGFR in the cells transfected by 19Del, but not T790M or 19Del/T790M. Interestingly, PD-L1 expression increased in 293FT cells that were transfected with 19Del, whereas transfection of 19Del/T790M resulted in a higher level of PD-L1 expression (Fig. 5c and $\mathrm{d}$, and Additional file 1: Figure S10). Moreover, PI3K and MAPK pathway inhibition reduced PD-L1 expression in both 293FT cells transfected with 19Del/T790M mutation and H1975 cells containing EGFR-T790M mutation (Fig. $5 \mathrm{e}$ and $\mathrm{f}$ ). Unlike the mechanisms of $c-M E T$ amplification and HGF on the regulation of PD-L1, T790M-induced PD-L1 expression was suppressed after inhibition of the NF-kappa B pathway (Fig. 5e). These results suggest that the PI3K, MAPK, and NF-kappa B pathways are all involved in the regulation of PD-L1 in EGFR-T790M mutation-mediated EGFR-TKI resistant NSCLC cells.

\section{Restoration of the cytotoxic effect of human T lymphocytes in vivo via the downregulation of PD-L1 expression in EGFR-TKI resistant lung cancer}

To compare the immune escape capability of tumour cells among EGFR-TKI sensitive and resistant NSCLC in vivo, we generated EGFR-TKI sensitive and resistant NSCLC cells with $P D-L 1$ gene deletion, and its control cells (PC-9 ${ }^{\text {PD-L1- }}$ PC-9R ${ }^{\text {PD-L1- }}$, PC-9 ${ }^{\text {PD-L1+ }}$, and PC$9 \mathrm{R}^{\mathrm{PD}-\mathrm{L} 1+}$ ) using the CRISPR-Cas9 knockout lentivirus. 

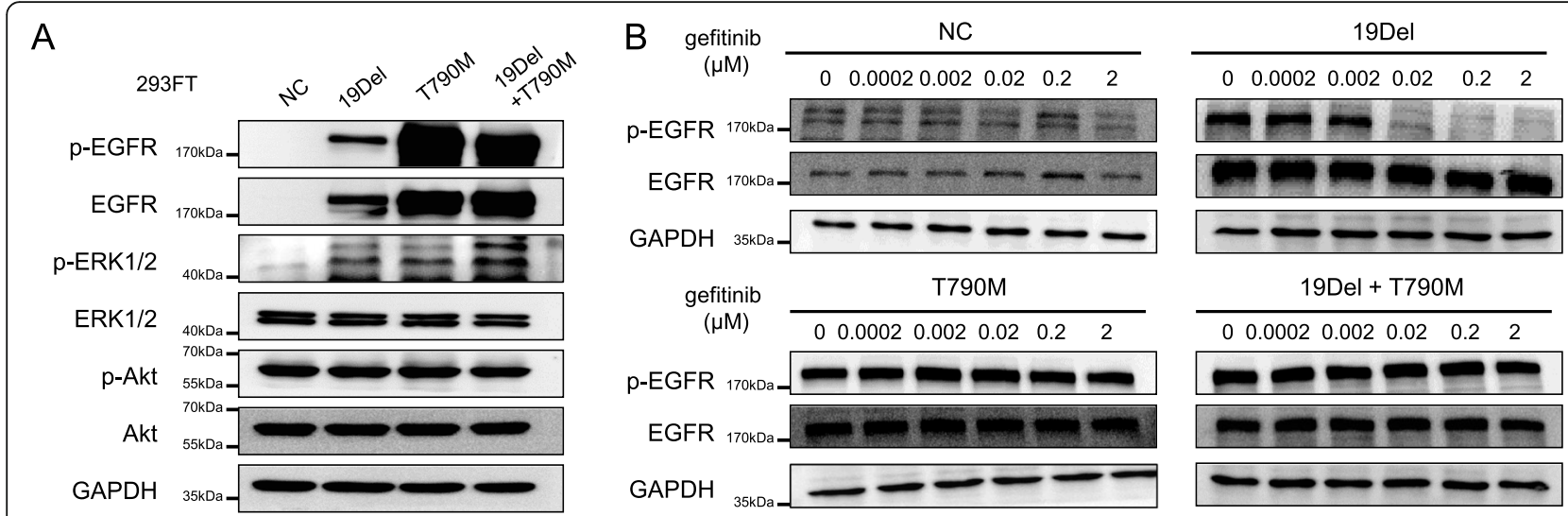

C PD-L1 Gene Fold

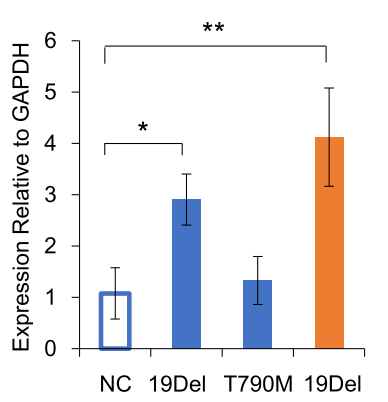

$+\mathrm{T} 790 \mathrm{M}$
D

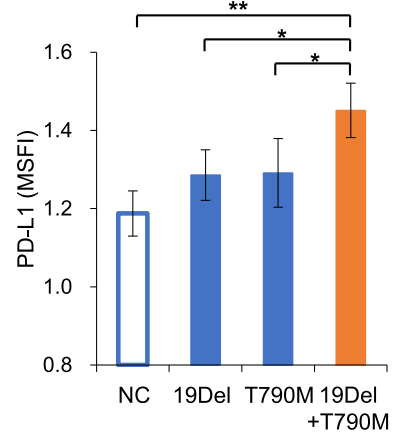

E

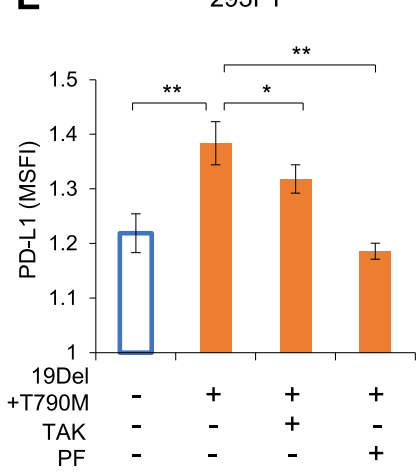

$\mathbf{F}$

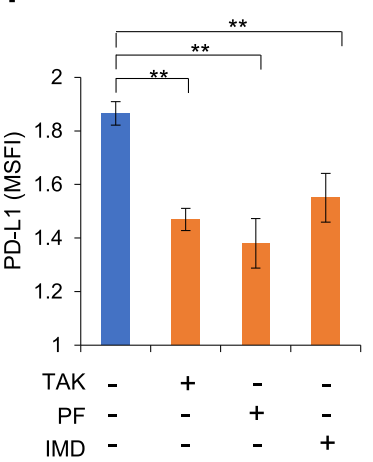

Fig. 5 EGFR-T790M secondary mutation upregulates PD-L1 expression in tumour cells through the PI3K/Akt, MAPK, and NF-kappa B signal pathways. a-d 293FT cells were transfected with control vector plasmid (NC), EGFR-19Del (19Del), or EGFR-T790M (T790M) mutation plasmids for 48-72 $\mathrm{h}$, then treated with/without gefitinib for a further $24 \mathrm{~h}$. All the cells were harvested and analyzed by western blotting, RT-qPCR and flow cytometry. Bars indicate SD. ${ }^{*} P<0.05$; ${ }^{* *} P<0.01$. e 293FT cells were transfected as described above for $48 \mathrm{~h}$, and then treated with TAK-733 (TAK, $0.3 \mu \mathrm{mol} / \mathrm{L}$ ) or PF-04691502 (PF, $0.3 \mu \mathrm{mol} / \mathrm{L}$ ) for an additional $12 \mathrm{~h}$. PD-L1 expression was evaluated by flow cytometry. Bars indicate SD. *

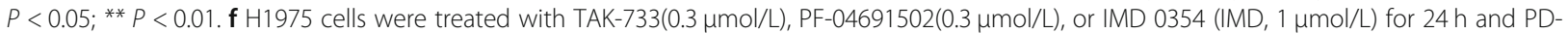
L1 expression was evaluated by flow cytometry. Bars indicate SD. ${ }^{*} P<0.05 ;{ }^{*} P<0.01$. All experiments were performed at least thrice

We confirmed the base sequence of the $P D-L 1$ gene in the cells to confirm knockdown efficacy (Fig. 6a). The PC-9 and PC-9R cells exhibited the same sensitivity to EGFR-TKIs after deletion or overexpression of the $P D$ $L 1$ gene (Additional file 1: FiguresS11-S12). Meanwhile, overexpression PD-L1 has no influence on EGFR expression (Additional file 1: Figure S12B). Then, all four cells were injected subcutaneously in NOD-SCID mice to build the xenograft models described in materials and methods. In addition, human immunocyte mixtures rather than PBMC [39] were injected into the NODSCID mice to kill the xenografts more effectively. Figure $6 \mathrm{~b}$ shows that low PD-L1 expression in PC$9^{\mathrm{PD}-\mathrm{L} 1-}$ and $\mathrm{PC}-9 \mathrm{R}^{\mathrm{PD}-\mathrm{L} 1-}$ tumours shows the effectiveness of PD-L1 gene deletion. Moreover, tumours in PC$9^{\mathrm{PD}-\mathrm{L} 1+}$ group were degraded after treatment with human immunocyte mixtures, however tumours in the PC$9 \mathrm{R}^{\mathrm{PD}-\mathrm{L} 1+}$ group did not respond to the treatment, suggesting an immune suppression environment in PC$9 \mathrm{R}^{\mathrm{PD}-\mathrm{L} 1+}$ tumours. With respect to the PD-L1 gene deletion groups, the tumours in the PC- $9^{\mathrm{PD}-\mathrm{L} 1-}$ and $\mathrm{PC}$ $9 \mathrm{R}^{\text {PD-L1- }}$ groups shrank remarkably, suggesting an antitumour effect of $\mathrm{T}$ cells restored after PD-L1 depletion on tumour cells (Fig. 6c). Owing to the short survival time in NOD-SCID mice, the percentage and distribution of human CD8+ $\mathrm{T}$ cells and other human immune cells could not be detected in vivo after treatment with human immunocyte mixtures for more than 1 month.

The results of H\&E staining indicated no significant morphologic abnormalities in any group. In addition, the percentage of $\mathrm{Ki}^{+} 7^{+}$cells and apoptotic cells (Fig. 6d-e) indicated that immunocyte mixtures treatment decreased the proliferation of tumour cells (Ki67-positive) and promoted apoptosis of tumour cells (TUNEL positive) in the PC-9 groups (PC-9 $9^{\mathrm{PD}-\mathrm{L} 1+}$ and $\left.\mathrm{PC}-9^{\mathrm{PD}-\mathrm{L} 1-}\right)$. Alternatively, there was no significant influence on the PC-9 ${ }^{\mathrm{PD}-\mathrm{L} 1+}$ tumours, indicating immune depression tumour microenvironment (TME) on xenografts in vivo after acquired EGFR-TKIs resistance. In contrast, PC$9 \mathrm{R}^{\mathrm{PD}-\mathrm{L1} 1-}$ tumours responded to the treatment with 


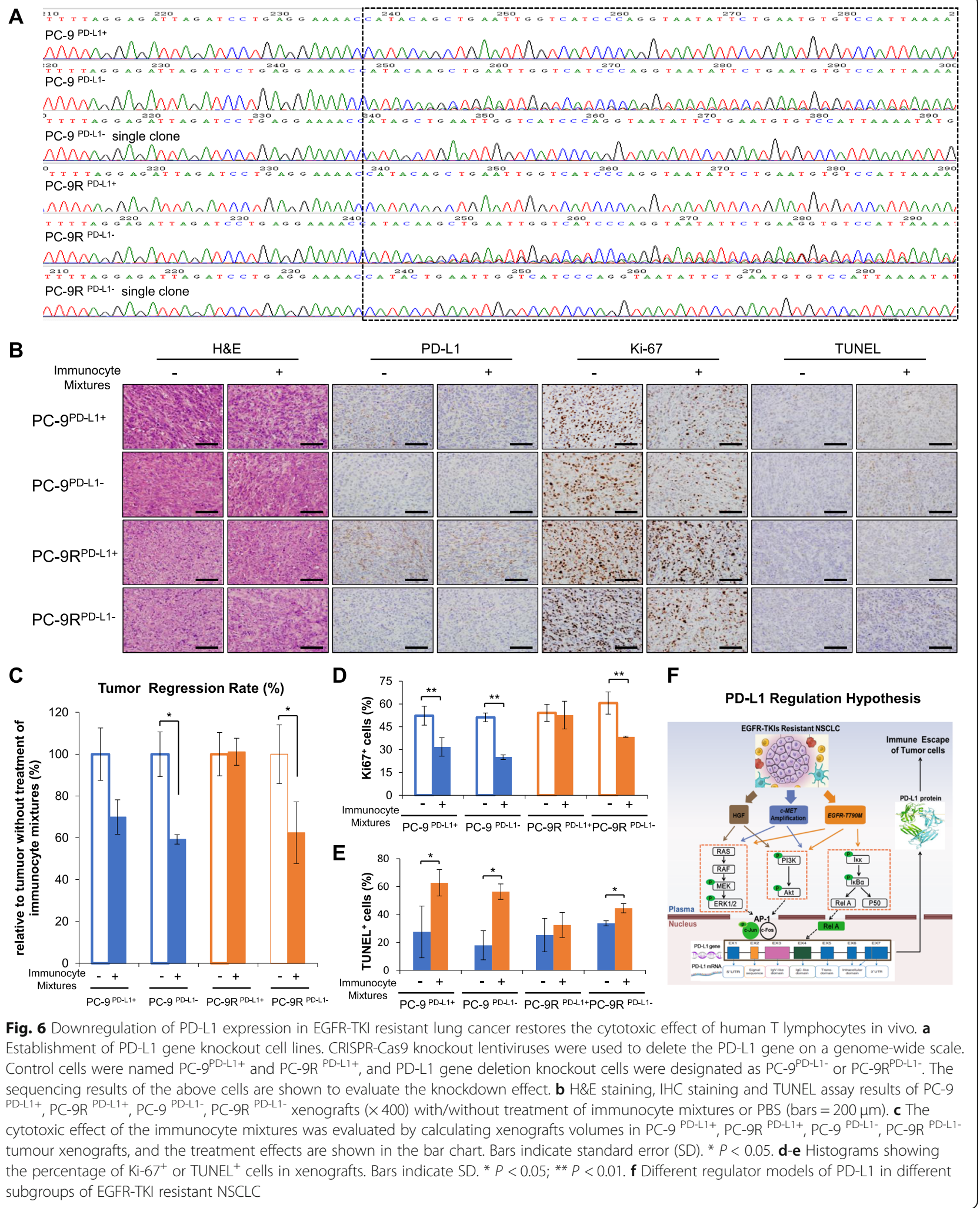

significantly lower percentage of Ki67 positive cells and a higher percentage of TUNEL-positive cells. These results clearly showed that overexpression of PD-L1 in
PC-9R cells mediated the immune escape of tumour cells, whereas PD-L1 depletion successfully restored the cytotoxicity of lymphocytes to PC-9R cells in vivo. 


\section{Discussion}

The PD-1/PD-L1 axis plays a prominent role in immune suppression of the tumour microenvironment [40, 41], and patients with higher tumour PD-L1 expression achieve improved responses to treatment with anti-PD-1 and anti-PD-L1 therapy, compared with patients with lower PD-L1 expression. Thus, determining the regulatory mechanisms of PD-L1 in tumours is meaningful and necessary. Recently, PD-L1 was found to increase after the development of resistance to BRAF inhibitors [35]. However, very few studies have examined the connection between EGFR-TKI resistance and PD-L1 expression in lung cancer. In this study, the paired EGFR-TKI sensitive and resistant specimens and TCGA datasets suggested that PD-L1 expression may be different after acquisition of EGFR-TKI resistance, and PD-L1 expression was found to be positively correlated to c-MET expression. Our data suggest that HGF, $c-M E T$ amplification, and EGFR T790M mutation can upregulate PD-L1 expression and promote immune escape capability in NSCLC, and that the relative regulatory mechanisms of PD-L1 expression among three subtypes may be vary. Other EGFR-TKI resistant mechanisms, such as EMT, PTEN loss, and activation of IGF-1R, should be further investigated to determine their influence on PD-L1 expression on EGFRTKIs resistant NSCLC.

The PI3K/Akt and MAPK signaling pathways are widely reported to participate in the regulation of PD-L1 in many tumours, and NF-kappa B was found to be involved in the EGFR-TKI induced downregulation of PDL1 in EGFR-mutant NSCLC [38]. In our study, we found that the PI3K-Akt and MAPK signaling pathways are both involved in the overexpression of PD-L1 induced by $c-M E T$ amplification, the HGF/c-MET axis, and EGFR-T790M mutation. We further identified that AP-1 may be involved in HGF-induced PD-L1 expression. Alternatively, the NF-kappa B pathway was involved in EGFR-T790M mutation-induced PD-L1 expression and had no significant influence on PD-L1 expression induced by HGF and c-MET amplification (Fig. 5f; Additional file 1: Figure S5, S9). This suggests that the NF-kappa B pathway is largely involved in EGFR-related PD-L1 expression, and less important in bypass resistance induced-PD-L1 expression. These results suggest that PD-L1 regulation in NSCLC with different EGFRTKI resistant mechanisms may not be the same. Moreover, we infer that some EGFR-TKI resistant mechanisms related to the abnormal activation of the PI3K/Akt pathway, such as PTEN loss, may also increase PD-L1 expression.

EGFR-TKI treatment is the first-line therapy for EGFR mutant NSCLC. However, whether immunotherapy may be used in the treatment of EGFR-TKI resistant EGFR mutant NSCLC is yet to be determined. Previous studies have shown that EGFR mutations are associated with a low response rate to PD-1/PD-L1 inhibitors in NSCLC, and objective responses were observed in 1 of 28 (3.6\%) EGFR-mutant patients versus 7 of 30 (23.3\%) EGFR wild-type patients [15]. However, in patients with EGFR mutation, the objective response rate (ORR) of immunotherapy in the PD-L1 high expression group was $12.2 \%$, while it was only $3.6 \%$ in the PD-L1 low expression group [42]. Haratani [43] found that T790M-negative patients with EGFR mutation-positive NSCLC are more likely to benefit from Nivolumab (anti-human PD-1 monoclonal antibodies) after EGFR-TKI treatment, possibly as a result of a higher PD-L1 expression level, when compared with T790M-positive patients, which indicates that patients with other resistance mechanisms, such as MET activation, may have higher response rates compared with those with T790M mutations in NSCLC. Therefore, despite the lower response of PD-1/PD-L1 therapy in EGFR mutant compared with EGFR wild-type patients, higher PD-L1 expression still indicates a better response to anti-PD-1/PD-L1 inhibitors in EGFR mutant advanced lung cancer patients who acquired EGFR-TKI resistance. In addition, PD-L1 expression and the response rate may be different among EGFR-TKI resistant advanced NSCLC patients. In our study, we found that some EGFR-TKI mechanisms may upregulate PD-L1 expression and promote the immune escape ability of EGFR-TKIs resistant NSCLC tumours, but it does not indicate an absolute response to anti-PD-1/PD-L1 therapies. A series of factors, such as tumour mutation burden (TMB), co-occurring genomic alterations, microsatellite instability (MSI), tumour-infiltrating lymphocytes (TILs), and immunogenic/no-immunogenic (hot or cold) TME $[11,12,44-48]$, have been considered as predictors of the response rate of patients to immune checkpoint therapies, i.e., that the efficacy of immune checkpoint therapies could be influenced by several factors. In our study, we found that TMB, PD-1 and PD-L1 expression in EGFR, $K R A S$, and $c-M E T$ mutant NSCLC might be vary (Additional file 1: Figure S1). Based on the PanCancer Atlas datasets, the mRNA expression level of PD-1 and PD-L1 in $c-M E T$ mutant NSCLC was higher than that with EGFR mutation. Therefore, whether the TME of $E G F R^{+} / c-M E T^{+}$mutant NSCLC, such as EGFR-TKI resistant NSCLC acquired $c-M E T$ amplification, is different from the $E G F R^{+} / c-M E T^{-}$mutant NSCLC, and the response rates to $\mathrm{PD}-1 / \mathrm{PD}-\mathrm{L} 1$ therapies require further investigation. Recently, the IMpower150 trial observed an improved overall survival with atezolizumab plus bevacizumab plus carboplatin plus paclitaxel (ABCP) versus bevacizumab plus carboplatin plus paclitaxel (BCP) in patients with sensitizing EGFR mutations, which shows a potential role of antiangiogenic drugs in enhancing the efficacy of immunotherapy in EGFR mutated patients 
[49]. Thus, whether EGFR-TKI resistant patients could ultimately benefit from checkpoint therapies and the best combination models among checkpoint therapy, chemotherapy, radiotherapy and targeted therapy need to be further investigated.

\section{Conclusions}

We found that acquired EGFR-TKI resistance promotes the immune escape in lung cancer by upregulating PDL1 expression. The PI3K-Akt, MAPK, and NF-kappa B signaling pathways and AP-1 are involved in the upregulation of PD-L1 induced by different EGFR-TKI resistant mechanisms. The results of our research may partially explain the different PD-L1 status in EGFR-TKI sensitive and resistant tumours and unveil the regulatory mechanisms of PD-L1 in EGFR-TKI resistant NSCLC. Our study provides insights into PD-L1 expression in the different subgroups of EGFR-TKI resistant NSCLC and may have specific implications for the possibility of immune-checkpoint therapy in different subgroups of EGFR-TKI resistant NSCLC.

\section{Supplementary information}

Supplementary information accompanies this paper at https://doi.org/10. 1186/s12943-019-1073-4

Additional file 1: Figure S1. The tumor mutation burden (TMB), PD-L1, PD-1 and CTLA-4 expression in EGFR, C-MET and KRAS mutant subgroups basing on TCGA Datasheet (Lung Adenocarcinoma, PanCancer Atlas). Figure S2. PD-L1 Expression after stimulation of HGF. Figure S3. A. The percentage of DC cells in PBMC separated from health donators. Figure S4. A. IFN- $\gamma$ concentration in the supernatant of co-culture systems. Figure S5. Inhibition of NF-kappa B pathway may not be involved in HGFinduced PD-L1 expression in NSCLC. Figure S6. PD-L1 expression was increased in EGFR-TKls resistant cells. Figure S7. A. c-MET Si-RNAs downregulate the c-MET expression in PC-9 and PC-9 cells. Figure S8. HLA-ABC expression level in PC-9 and PC-9R cells were measured by flow cytometry. Figure S9. Inhibition of NF-kappa B pathway slightly decreases PD-L1 expression induced by c-MET amplification. Figure S10. 293FT cells were transfected with control vector plasmid (NC), EGFR-19Del (19Del), or EGFR-T790M (T790M) mutation plasmids for 48-72 h, then treated with/ without gefitinib for a further $24 \mathrm{~h}$. All the cells were harvested and analysed by western blotting, RT-qPCR and flow cytometry. Figure S11. PC-9 and PC-9R cells remain the same sensitivity to gefitinib after deletion of PD-L1 gene. Figure S12. Overexpression of PD-L1 on PC-9 cells has no significant influence on EGFR expression and EGFR-TKls sensitivity. Supplementary materials and methods.

Additional file 2: Table S1. Basic information of EGFR-TKIs resistant NSCLC patients.

Additional file 3: Quantitation results of Western blots.

\section{Abbreviations}

ALK: Anaplastic lymphoma kinase; AP-1: Activator protein; EGFRTKIs: Epidermal growth factor receptor-tyrosine kinase inhibitors; H\&E: Hematoxylin and eosin; HGF: Hepatocyte growth factor; IFN-

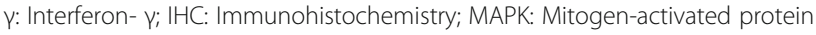
kinase; MSI: Microsatellite instability; NSCLC: Non-small cell lung cancer; PD1: Programmed death-1; PD-L1: Programmed death-ligand 1; PFS: Progression-free survival; (PI3K)/Akt: Phosphoinositide 3-kinase; TILs: Tumour-infiltrating lymphocytes; TMB: Tumour mutation burden; TME: Tumour microenvironment

\section{Acknowledgments}

We thank Central Laboratory of Nanfang Hospital, Southern Medical University for providing technical support. We thank LetPub (www.letpub. com) for providing linguistic assistance during the preparation of this manuscript.

\section{Authors' contributions}

Conception and design: WW. Development of methodology: SP, WW, SY Acquisition of data (provided animals, acquired and managed patients, provided facilities, etc.): SP, RW, SY, WW. Analysis and interpretation of data (e.g., statistical analysis, biostatistics, computational analysis): SP, RW, WW. Writing, review, and/or revision of the manuscript: SP, WW. Administrative, technical, or material support (i.e., reporting or organizing. data, constructing databases): SP, RW, XZ, YM, LZ, NA, SA, KL, WW. All authors read and approved the final manuscript.

\section{Funding}

This work was supported by National Natural Science Foundation of China Grant (81172243 and 81572966 to W. Wang) and Natural Science Foundation of Guangdong Province (2017A030313883 to W. Wang).

\section{Availability of data and materials}

All the data generated or analyzed during this study are included in this published article and its supplementary files.

Ethics approval and consent to participate

The research presented here has been performed in accordance with the Declaration of Helsinki and has been approved by the ethics committee of Nanfang hospital, Southern Medical University, China.

\section{Consent for publication}

All of the authors of this article have participated in the planning and drafting and all of the authors listed have read and approved the final version including details and images. Written informed consent for the publication has been obtained from all of the authors. The patients were informed of the publication and have provided their written informed consent.

\section{Competing interests}

The authors declare that they have no competing interests.

\section{Author details}

${ }^{1}$ Department of Radiation Oncology, Nanfang Hospital, Southern Medical University, Guangzhou, People's Republic of China. ${ }^{2}$ Center for Clinical Medicine Research, Nanfang Hospital, Southern Medical University, Guangzhou 510515, People's Republic of China. ${ }^{3}$ Divisions of Medical Oncology, Cancer Research Institute, Kanazawa University, Kanazawa, Ishikawa, Japan.

Received: 17 March 2019 Accepted: 12 September 2019 Published online: 20 November 2019

\section{References}

1. Siegel RL, Miller KD. Cancer statistics, 2019. CA Cancer J Clin. 2019;69:7-34.

2. Mok TS, Wu YL, Thongprasert S, Yang CH, Chu DT, Saijo N, Sunpaweravong P, Han BH, Margono B, Ichinose $Y$, et al. Gefitinib or carboplatin-paclitaxel in pulmonary adenocarcinoma. N Engl J Med. 2009;361:947-57.

3. Sequist LV, Yang JC, Yamamoto N, O'Byrne K, Hirsh V, Mok T, Geater SL, Orlov S, Tsai CM, Boyer M, et al. Phase III study of afatinib or cisplatin plus pemetrexed in patients with metastatic lung adenocarcinoma with EGFR mutations. J Clin Oncol. 2013;31:3327-34.

4. Huang WF, Liu AH, Zhao HJ, Dong HM, Liu LY, Cai SX. BIM gene polymorphism lowers the efficacy of EGFR-TKls in advanced nonsmall cell lung Cancer with sensitive EGFR mutations: a systematic review and metaanalysis. Medicine (Baltimore). 2015;94:e1263.

5. Mao C, Qiu LX, Liao RY, Du FB, Ding H, Yang WC, Li J, Chen Q. KRAS mutations and resistance to EGFR-TKls treatment in patients with non-small cell lung cancer: a meta-analysis of 22 studies. Lung Cancer. 2010;69:272-8.

6. Sullivan I, Planchard D. Osimertinib in the treatment of patients with epidermal growth factor receptor T790M mutation-positive metastatic non- 
small cell lung cancer: clinical trial evidence and experience. Ther Adv Respir Dis. 2016;10:549-65.

7. Gou LY, Li AN, Yang J, Zhang XC, Su J, Yan HH, Xie Z, Lou NN, Liu SY, Dong ZY, et al. The coexistence of MET over-expression and an EGFR T790M mutation is related to acquired resistance to EGFR tyrosine kinase inhibitors in advanced non-small cell lung cancer. Oncotarget. 2016;7:51311-9.

8. Wu YL, Soo RA, Locatelli G, Stammberger U, Scagliotti G, Park K. Does c-met remain a rational target for therapy in patients with EGFR TKIresistant non-small cell lung cancer? Cancer Treat Rev. 2017;61:70-81.

9. Zhang Q, Zhang XC, Yang JJ, Yang ZF, Bai Y, Su J, Wang Z, Zhang Z, Shao Y, Zhou Q, et al. EGFR L792H and G796R: two novel mutations mediating resistance to the third-generation EGFR tyrosine kinase inhibitor Osimertinib. J Thorac Oncol. 2018;13:1415-21.

10. Ko B, He T, Gadgeel S, Halmos B. MET/HGF pathway activation as a paradigm of resistance to targeted therapies. Ann Transl Med. 2017;5:4.

11. Brahmer JR, Tykodi SS, Chow LQ, Hwu WJ, Topalian SL, Hwu P, Drake CG, Camacho LH, Kauh J, Odunsi K, et al. Safety and activity of anti-PD-L1 antibody in patients with advanced cancer. N Engl J Med. 2012:366:2455-65.

12. Garon EB, Rizvi NA, Hui R, Leighl N, Balmanoukian AS, Eder JP, Patnaik A, Aggarwal C, Gubens M, Horn L, et al. Pembrolizumab for the treatment of non-small-cell lung cancer. N Engl J Med. 2015;372:2018-28.

13. Dong ZY, Zhong WZ, Zhang XC, Su J, Xie Z, Liu SY, Tu HY, Chen HJ, Sun YL, Zhou Q, et al. Potential predictive value of TP53 and KRAS mutation status for response to PD-1 blockade immunotherapy in lung adenocarcinoma. Clin Cancer Res. 2017;23:3012-24.

14. Herbst RS, Baas P, Kim DW, Felip E, Perez-Gracia JL, Han JY, Molina J, Kim JH, Arvis CD, Ahn MJ, et al. Pembrolizumab versus docetaxel for previously treated, PD-L1-positive, advanced non-small-cell lung cancer (KEYNOTE-010): a randomised controlled trial. Lancet. 2016;387:1540-50.

15. Gainor JF, Shaw AT, Sequist LV, Fu X, Azzoli CG, Piotrowska Z, Huynh TG, Zhao L, Fulton L, Schultz KR, et al. EGFR mutations and ALK rearrangements are associated with low response rates to PD-1 pathway blockade in non-small cell lung Cancer: a retrospective analysis. Clin Cancer Res. 2016:22:4585-93.

16. Bylicki O, Paleiron N, Margery J, Guisier F, Vergnenegre A, Robinet $G$, Auliac JB, Gervais R, Chouaid C. Targeting the PD-1/PD-L1 immune checkpoint in EGFR-mutated or ALK-Translocated non-small-cell lung Cancer. Target Oncol. 2017;12:563-9.

17. Garassino MC, Cho BC, Kim JH, Mazieres J, Vansteenkiste J, Lena H, Corral Jaime J, Gray JE, Powderly J, Chouaid C, et al. Durvalumab as third-line or later treatment for advanced non-small-cell lung cancer (ATLANTIC): an open-label, single-arm, phase 2 study. Lancet Oncol. 2018;19:521-36.

18. Lin JJ, Gainor JF. ATLANTIC: a sea change in immunotherapy for oncogenedriven lung cancer? Lancet Oncol. 2018;19:438-9.

19. Antonia SJ, Brahmer JR, Khleif S, Balmanoukian AS, Ou SI, Gutierrez M, Kim D, Kim S, Ahn M, Leach J. Phase 1/2 study of the safety and clinical activity of durvalumab in patients with non-small cell lung cancer (NSCLC). Ann Oncol. 2016;27(suppl_6):vi416-54.

20. Su S, Dong ZY, Xie Z, Yan LX, Li YF, Su J, Liu SY, Yin K, Chen RL, Huang SM, Chen ZH, Yang JJ, Tu HY, Zhou Q, Zhong WZ, Zhang XC, Wu YL. Strong PD-L1 expression predicts poor response and denovo resistance to EGFR TKIs among non-small cell lung cancer patients with EGFR mutation. J Thorac Oncol. 2018;13:1668-75.

21. Akbay EA, Koyama S, Carretero J, Altabef A, Tchaicha JH, Christensen CL, Mikse OR, Cherniack AD, Beauchamp EM, Pugh TJ, et al. Activation of the PD-1 pathway contributes to immune escape in EGFR-driven lung tumors. Cancer Discov. 2013;3:1355-63.

22. Liu T, Sun $Q$, Li Q, Yang $H$, Zhang $Y$, Wang $R$, Lin $X$, Xiao $D$, Yuan $Y$, Chen L, Wang W. Dual PI3K/mTOR inhibitors, GSK2126458 and PKI587, suppress tumor progression and increase radiosensitivity in nasopharyngeal carcinoma. Mol Cancer Ther. 2015;14:429-39.

23. Yang H, Wang R, Peng SL, Chen LH, Li Q, Wang W. Hepatocyte growth factor reduces sensitivity to the epidermal growth factor receptor-tyrosine kinase inhibitor, gefitinib, in lung adenocarcinoma cells harboring wild-type EGFR. Oncotarget. 2016;7:16273-81.

24. Zhang Y, Zheng L, Ding Y, Li Q, Wang R, Liu T, Sun Q, Yang H, Peng S, Wang W, Chen L. MiR-20a induces cell Radioresistance by activating the PTEN/PI3K/Akt signaling pathway in hepatocellular carcinoma. Int J Radiat Oncol Biol Phys. 2015;92:1132-40.
25. Liu X, Liu L, Zhang H, Shao Y, Chen Z, Feng X, Fang H, Zhao C, Pan J, Zhang H, Zeng C, Cai D. MiR-146b accelerates osteoarthritis progression by targeting alpha-2-macroglobulin. Aging (Albany NY). 2019;11:6014-28.

26. Wang W, Nishioka Y, Ozaki S, Jalili A, Abe S, Kakiuchi S, Kishuku M, Minakuchi K, Matsumoto T, Sone S. HM1.24 (CD317) is a novel target against lung cancer for immunotherapy using anti-HM1.24 antibody. Cancer Immunol Immunother. 2009;58:967-76.

27. Balan M, Mier y Teran E, Waaga-Gasser AM, Gasser M, Choueiri TK, Freeman G, Pal S. Novel roles of c-met in the survival of renal cancer cells through the regulation of HO-1 and PD-L1 expression. J Biol Chem. 2015;290:8110-20.

28. Ge $Y, X i H$, Zhang $X G$. Vaccination with immature dendritic cells combined with CD40mAb induces protective immunity against B lymphoma in hu-SCID mice. Biomed Pharmacother. 2010;64:487-92.

29. Yano S, Wang W, Li Q, Matsumoto K, Sakurama H, Nakamura T, Ogino H, Kakiuchi S, Hanibuchi M, Nishioka Y, et al. Hepatocyte growth factor induces gefitinib resistance of lung adenocarcinoma with epidermal growth factor receptor-activating mutations. Cancer Res. 2008;68:9479-87.

30. Seol DW, Chen Q, Zarnegar R. Transcriptional activation of the hepatocyte growth factor receptor (c-met) gene by its ligand (hepatocyte growth factor) is mediated through AP-1. Oncogene. 2000;19:1132-7.

31. Pardoll DM. The blockade of immune checkpoints in cancer immunotherapy. Nat Rev Cancer. 2012;12:252-64.

32. Hao NB, Tang B, Wang GZ, Xie R, Hu CJ, Wang SM, Wu YY, Liu E, Xie X, Yang SM. Hepatocyte growth factor (HGF) upregulates heparanase expression via the PI3K/Akt/NF-kappaB signaling pathway for gastric cancer metastasis. Cancer Lett. 2015;361:57-66.

33. Proto JD, Tang Y, Lu A, Chen WC, Stahl E, Poddar M, Beckman SA, Robbins PD, Nidernhofer $L$, Imbrogno K, et al. NF-kappaB inhibition reveals a novel role for HGF during skeletal muscle repair. Cell Death Dis. 2015;6:e1730.

34. Wang W, Li Q, Takeuchi S, Yamada T, Koizumi H, Nakamura T, Matsumoto K, Mukaida N, Nishioka Y, Sone S, et al. Met kinase inhibitor E7050 reverses three different mechanisms of hepatocyte growth factor-induced tyrosine kinase inhibitor resistance in EGFR mutant lung cancer. Clin Cancer Res. 2012;18:1663-71.

35. Jiang X, Zhou J, Giobbie-Hurder A, Wargo J, Hodi FS. The activation of MAPK in melanoma cells resistant to BRAF inhibition promotes PD-L1 expression that is reversible by MEK and PI3K inhibition. Clin Cancer Res. 2013;19:598-609.

36. Engelman JA, Zejnullahu K, Mitsudomi T, Song YC, Hyland C, Park JO, Lindeman N, Gale CM, Zhao XJ, Christensen J, et al. MET amplification leads to gefitinib resistance in lung cancer by activating ERBB3 signaling. Science. 2007:316:1039-43.

37. Bean J, Brennan C, Shih JY, Riely G, Viale A, Wang L, Chitale D, Motoi N, Szoke J, Broderick S, et al. MET amplification occurs with or without T790M mutations in EGFR mutant lung tumors with acquired resistance to gefitinib or erlotinib. Proc Natl Acad Sci U S A. 2007;104:20932-7.

38. Lin K, Cheng J, Yang T, Li Y, Zhu B. EGFR-TKI down-regulates PD-L1 in EGFR mutant NSCLC through inhibiting NF-kappaB. Biochem Biophys Res Commun. 2015;463:95-101.

39. Sanmamed MF, Rodriguez I, Schalper KA, Onate C, Azpilikueta A, RodriguezRuiz ME, Morales-Kastresana A, Labiano S, Perez-Gracia JL, Martin-Algarra S, et al. Nivolumab and Urelumab enhance antitumor activity of human $T$ lymphocytes engrafted in Rag2-/-IL2Rgammanull Immunodeficient mice. Cancer Res. 2015;75:3466-78.

40. Li Y, Liang L, Dai W, Cai G, Xu Y, Li X, Li Q, Cai S. Prognostic impact of programed cell death-1 (PD-1) and PD-ligand 1 (PD-L1) expression in cancer cells and tumor infiltrating lymphocytes in colorectal cancer. Mol Cancer. 2016;15:55.

41. Kammerer-Jacquet SF, Medane S, Bensalah K, Bernhard JC, Yacoub M, Dupuis F, Ravaud A, Verhoest G, Mathieu R, Peyronnet B, et al. Correlation of C-MET expression with PD-L1 expression in metastatic clear cell renal cell carcinoma treated by Sunitinib first-line therapy. Target Oncol. 2017;12:487-94

42. Garassino MC, Cho BC, Gray JE, Mazières J, Park K-S, Soo RA, Dennis P, Huang Y, Wadsworth C, Rizvi N. 82ODurvalumab in $\geq 3$ rd-line EGFR mutant/ ALK+, locally advanced or metastatic NSCLC: Results from the phase 2 ATLANTIC study. 2017;28(suppl_2):ii28-51.

43. Haratani K, Hayashi H, Tanaka T, Kaneda H, Togashi Y, Sakai K, Hayashi K, Tomida S, Chiba Y, Yonesaka $\mathrm{K}$, et al. Tumor immune microenvironment and nivolumab efficacy in EGFR mutation-positive non-small-cell lung 
cancer based on T790M status after disease progression during EGFR-TKI treatment. Ann Oncol. 2017;28:1532-9.

44. Gettinger SN, Horn L, Gandhi L, Spigel DR, Antonia SJ, Rizvi NA, Powderly JD, Heist RS, Carvajal RD, Jackman DM, et al. Overall survival and long-term safety of Nivolumab (anti-programmed death 1 antibody, BMS-936558, ONO-4538) in patients with previously treated advanced non-small-cell lung Cancer. J Clin Oncol. 2015;33:2004-12.

45. Topalian SL, Hodi FS, Brahmer JR, Gettinger SN, Smith DC, McDermott DF, Powderly JD, Carvajal RD, Sosman JA, Atkins MB, et al. Safety, activity, and immune correlates of anti-PD-1 antibody in cancer. N Engl J Med. 2012:366:2443-54.

46. Brahmer J, Reckamp KL, Baas P, Crino L, Eberhardt WE, Poddubskaya E, Antonia S, Pluzanski A, Vokes EE, Holgado E, et al. Nivolumab versus Docetaxel in advanced squamous-cell non-small-cell lung Cancer. N Engl J Med. 2015;373:123-35.

47. Ribas A, Hu-Lieskovan S. What does PD-L1 positive or negative mean? J Exp Med. 2016;213:2835-40.

48. Rooney MS, Shukla SA, Wu CJ, Getz G, Hacohen N. Molecular and genetic properties of tumors associated with local immune cytolytic activity. Cell. 2015;160:48-61

49. Reck M, Mok TSK, Nishio M, Jotte RM, Cappuzzo F, Orlandi F, Stroyakovskiy D, Nogami N, Rodriguez-Abreu D, Moro-Sibilot D, et al. Atezolizumab plus bevacizumab and chemotherapy in non-small-cell lung cancer (IMpower150): key subgroup analyses of patients with EGFR mutations or baseline liver metastases in a randomised, open-label phase 3 trial. Lancet Respir Med. 2019;7:387-401.

\section{Publisher's Note}

Springer Nature remains neutral with regard to jurisdictional claims in published maps and institutional affiliations.

Ready to submit your research? Choose BMC and benefit from:

- fast, convenient online submission

- thorough peer review by experienced researchers in your field

- rapid publication on acceptance

- support for research data, including large and complex data types

- gold Open Access which fosters wider collaboration and increased citations

- maximum visibility for your research: over $100 \mathrm{M}$ website views per year

At $\mathrm{BMC}$, research is always in progress.

Learn more biomedcentral.com/submissions 